\title{
SEGMENTASI TERM SUNNAH DI INDONESIA
}

\author{
Sanip Nasrullah, Reza Pahlevi Dalimunthe \\ Pascasarjana Uin Sunan Gunung Djati Bandung, Indonesia \\ sanifnasrullah77@gmail.com
}

\begin{abstract}
Abstrak:
Term sunnah adalah salah satu kata yang sangat familiar di kalangan umat Islam, khususnya di Indonesia. Sunnah adalah kata yang digunakan untuk menunjukkan suatu perbuatan atau amalan yang disandarkan langsung kepada Nabi Saw. dari segi perkataan, perbuatan, dan persetujuan (taqrir). Di Indonesia pada beberapa oknum atau kalangan tertentu, term sunnah digunakan bukan untuk menunjukkan suatu amalan atau perbuatan yang disandarkan kepada Nabi sebagaimana yang telah disebutkan, akan tetapi term sunnah tersebut digunakan sebagai kata yang dilekatkan pada penamaan sebuah objek tertentu. Dengan menggunakan survey literature, artikel ini mencoba untuk mengkaji makna sunnah yang sebenarnya menurut para ulama, juga untuk meneliti beberapa objek yang menggunakan kata sunnah dalam penamaannya. Data yang didapat melalui penelusuran naskah dari berbagai sumber tentang penamaan dengan memakai kata sunnah ini akan dikaji ulang untuk kemudian dikomparasikan dengan makna sunnah yang sesungguhnya. Hasilnya, Merupakan suatu kesalahan apabila kata sunnah digunakan untuk penamaan suatu objek, sebagaimana yang terjadi di Indonesia yang jelas-jelas tidak pernah terjadi di zaman Rasulullah; baik yang secara langsung dilakukan oleh beliau, Sahabat maupun Tabi'in. Hal ini akan memunculkan asumsi bahwa suatu objek seperti para Ustadz, toko, komunitas, radio, tv, dan objek-objek lainnya yang tidak menggunakan kata sunnah dalam penamaannya akan dianggap bid'ah. Hal ini akan berdampak pada bingungnya ummat dan konsekuensinya adalah ummat akan menjauh serta akan muncul sikap meremehkan dan saling menyalahkan dan akan menimbulkan perpecahan. Jika-pun memang harus memakai kata sunnah untuk nama suatu objek, maka hal itu harus diakui hanya sebatas label saja dan bukan untuk menunjuk pada makna dari kata sunnah yang sebenarnya.
\end{abstract}

Kata Kunci: Segmentasi, Sunnah, Indonesia

\begin{abstract}
Term sunnah is one of the words that are very familiar among Muslims, especially in Indonesia. Sunnah is a word used to indicate an action or practice that is based directly on the Prophet. in terms of words, deeds, and agreements (taqrir). In Indonesia, in certain elements or circles, the term sunnah is used not to indicate a deed or act that is based on the Prophet as mentioned, but the term sunnah is used as a word attached to the naming of a particular object. Using a literature survey, this article tries to examine the true meaning of the sunnah according to the scholars, as well as to examine some objects that use the word sunnah in its naming. Data obtained through searching manuscripts from various sources about naming using the word sunnah will be reviewed and then compared with the true meaning of the sunnah. The result, it is a mistake if the word sunnah is used for naming an object, as happened in Indonesia which never happened in the time of the Prophet;
\end{abstract}




\section{AT-TIBYAN}

Journal Of Qur'an and Hadis Studies

Vol. 2 No. 2 (Desember 2019)

both directly carried out by him, Friends and Tabi'in. This will give rise to the assumption that an object such as Ustadz, shops, communities, radio, tv, and other objects that do not use the word sunnah in naming it will be considered heresy. This will have an impact on the confusion of the Ummah and the consequence is that the Ummah will stay away and there will be an attitude of disparaging and blaming each other and will cause disunity. Even if it is necessary to use the word sunnah for the name of an object, then it must be recognized only as a label and not to refer to the true meaning of the word sunnah.

Keywords: Segmentation, Sunnah, Indonesia

\section{PENDAHULUAN}

Saat ini Umat Islam berada pada zaman dimana mereka tidak dapat melihat secara langsung bagaimana tatacara beribadah yang benar sesuai dengan contoh Nabi Muhammad Saw. Demikian pula, adalah sesuatu hal yang tidak dapat dilakukan jika ingin mencontoh para sahabat nabi dan generasi salafu al-shalih sesudah mereka (tabi'in dan tabi'u al-tabi'in) yang zamannya relatif lebih dekat dengan masa dimana Nabi Saw. hidup, sehingga dapat dipastikan bahwa mereka adalah generasi yang paling tahu bagaimana cara pelaksanaan ibadah yang benar sesuai dengan apa yang telah dicontohkan oleh Nabi Muhammad Saw sebagaimana legitimasi yang beliau sampaikan dalam sabdanya:

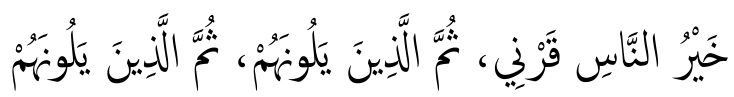

Artinya: Sebaik-baik manusia adalah yang hidup pada zamanku. Kemudian zaman sesudah mereka, lalu zaman sesudah mereka.(al-Bukhari, 1422, hlm. 3)

Karena berada dalam bentangan masa yang cukup jauh dengan generasi sahabat dan tabi'in juga tabi'ut tabi'in, maka satu-satunya cara yang dapat dilakukan oleh Umat Islam sekarang ini adalah dengan merujuk kepada teks yang menjelaskan keseluruhan dari ajaran agama yang dibawa oleh Nabi Muhammad Saw. yaitu al-Quran dan al-Hadits (sunnah) yang oleh para generasi islam terdahulu telah dibukukan, sehingga sampai dan dapat dipelajari oleh Umat Islam pada masa sekarang ini. Merupakan sebuah kewajiban bagi orang-orang yang beriman ketika mereka hendak melaksanakan suatu ibadah harus merujuk kepada al- Quran dan al-Hadits agar tidak terjadi kesalahan pada pelaksanaan ibadah yang menyebabkan amalan yang dilakukan menjadi sia-sia.(Kodir, 2016, hlm. 211)

Nabi Muhammad Saw pernah memperingatkan kepada para sahabatnya yang tentunya juga kepada umat islam seluruhnya, agar ketika 
Vol. 2 No. 2 (Desember 2019)

beramal harus benar-benar sesuai dengan apa yang beliau contohkan. Hal itu terindikasikan melalui hadits berikut:

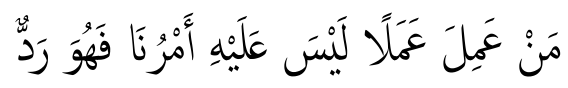

Artinya: Barang siapa yang mengerjakan suatu amalan yang tidak ada contoh dari kami, maka amalan itu tertolak.(al-Naisaburi, t.t, hlm. 1343)

Saat ini telah terjadi pergeseran makna dari pengertian awal kata sunnah yang dimaksudkan oleh syariat. Pada mulanya kata sunnah ditujukan untuk sebuah pengamalan, tetapi kemudian berubah menjadi sebuah penamaan bagi objek-objek tertentu sehingga muncul istilah-istilah baru dari kata sunnah yang sangat jauh sekali dari makna asalnya. Di Indonesia khususnya sudah mulai bermunculan penamaan dengan menggunakan kata sunnah dikalangan tertentu dalam beberapa segmen kegiatan yang mereka lakukan. Beberapa penamaan dengan menggunakan istilah sunnah tersebut telah dikenal di masyarakat dengan sebutan Bikers Sunnah, Kajian Sunnah, Masjid Sunnah, Ustad Sunnah, serta sebutan-sebutan lain dengan embelembel kata sunnah di dalamnya.

Berawal dari fenomena sebagaimana yang telah disebutkan, maka penelitian ini dilakukan dengan maksud untuk mengkaji tentang bagaimana hakikat sunnah yang sesungguhnya? Bagaimana penggunaan term sunnah di Indonesia? agar dapat melahirkan kesimpulan yang benar-benar sesuai dengan apa yang dimaksudkan oleh para ulama atau ahl al-ilmi berdasar pada kaidah-kaidah dan pengertian yang ada, sehingga dapat ditemukan istilah dan penggunaan kata sunnah yang tepat menurut syariat.

\section{PEMBAHASAN}

Pada pembahasan mengenai pengertian sunnah ini, perlu diketahui bahwa kata sunnah di kalangan ulama ahl al-Ilmi adalah merupakan sinonim dari kata hadis.(Al Siba'i, 1994, hlm. 53) Maka sebelum menjelaskan apa itu sunnah baik secara bahasa dan istilah, terlebih dahulu akan dijelaskan tentang apa itu hadis, Sebab, meski kata sunnah adalah sinonim dari kata hadis, namun ternyata para ulama memberikan pengertian tentang istilah sunnah dan hadis secara terpisah.

\section{Pengertian Hadis}

Secara bahasa, kata hadis berarti baru, yaitu الجحديُيْد مِنَ الأَشَيَاء (sesuatu yang baru), bentuk jamak hadis dengan makna ini adalah hidats, hudatsa' dan huduts, dan lawan katanya adalah qadim (sesuatu yang lama).(al-Sabbagh, 
Vol. 2 No. 2 (Desember 2019)

1972, hlm. 13) Subhi al-Shalih mengutip pendapat Ibnu Hajar al-Asqalani, bahwa yang dimaksud dengan hadis dalam tradisi syara' adalah sesuatu yang yang disandarkan kepada Nabi seolah-olah dimaksudkan sebagai bandingan dengan al-Quran yang bersifat qadim.(al-Salih, 1988, hlm. 5) Disamping memiliki arti baru, al-hadits juga mengandung arti dekat (القَرِيبُ), yaitu sesuatu yang dekat, yang belum lama terjadi dan juga berarti berita (الخحبرُ) yang sama

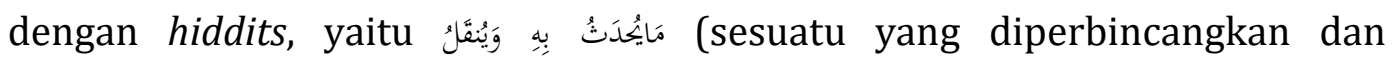
dipindahkan dari seseorang kepada orang lain).(al-Sabbagh, 1972, hlm. 13)

Al-Qasimi mengutip pendapat Abu al-Baqa , bahwa hadis merupakan bentuk isim dari kata al-tahdits, yaitu al-ikhbar (mengabarkan) kemudian dinamakan dengannya perkataan, perbuatan, atau ketetapan yang dinisbahkan kepada Nabi Saw. dan bentuk jamaknya adalah ahadits. Al-Farra' mengatakan bahwa bentuk tunggal dari ahadits adalah uhdutsah, kemudian ulama ahli bahasa menjadikannya sebagai bentuk jamak dari kata hadits sehingga tidak disebut uhdutsah al-Nabi, tetapi hadits al-Nabi(al-Qasimi, t.t., hlm. 61).

Dari sisi pendekatan kebahasaan ini, kata hadis digunakan baik dalam al-Quran maupun hadis sendiri. Dalam al-Quran misalnya dapat dilihat pada surah al-Thur ayat 34, surah al-Kahfi ayat 6 dan al-Duha ayat 11. Kemudian pada hadis dapat dilihat dalam beberapa sabda Rasul Saw. di antaranya hadis yang dinarasikan oleh Zayd bin Tsabit yang diriwayatkan oleh Abu Daud, Tirmidzi, dan Ahmad, yang menjelaskan tentang do'a Rasul Saw. terhadap orang yang menghafal dan menyampaikan suatu hadis dari beliau. Dalam alQuran surah al-Thur Allah berfirman:

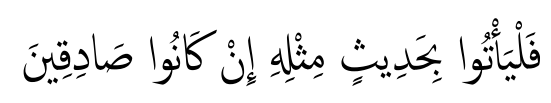

Artinya: Maka hendaklah mereka mendatangkan perkataan yang sama jika mereka memang benar. (QS. Al-Thur: 34)

Begitu pula dengan firman Allah dalam surah al-Kahfi berikut:

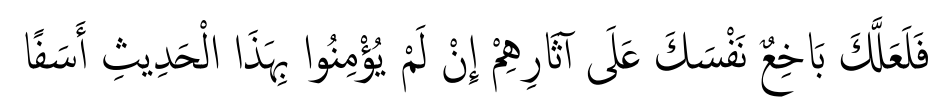

Artinya: Maka apakah baragkali kamu akan membunuh dirimu karena bersedih hati karena mereka berpaling, sekiranya mereka tidak beriman kepada keterangan ini. (QS. Al-Kahfi: 6) 
Vol. 2 No. 2 (Desember 2019)

'Ajjaj al-Khatib mengatakan bahwa yang dimaksud dengan kata hadis dalam ayat tersebut adalah al-Quran.(M. 'Ajjaj al-Khatib, 1989, hlm. 27) Kebanyakan ulama menggunakan kata hadis untuk kitab Allah, sehingga mereka menamakan kalam Allah dengan sebutan hadis Allah. Hal serupa sebagaimana yang terekam dalam sebuah riwayat:

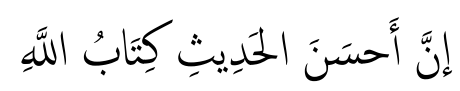

Artinya: Sesungguhnya sebaik-baik hadis [perkataan] adalah kitab Allah.(alSalih, 1988, hlm. 5)

Kata hadis juga bisa bermakna menyampaikan, seperti contoh dalam surah al-Duha ayat 11:

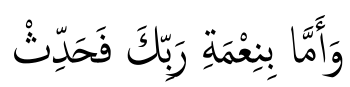

Artinya: Adapun berkenaan dengan nikmat Tuhanmu, maka hendaklah kamu menyebut-nyebutnya (dengan bersyukur). (QS. Al-Dhuha: 11)

Maksud dari kata fahaddits pada ayat tersebut adalah maka sampaikanlah apa yang telah kamu diutus untuknya.(al-Salih, 1988, hlm. 5) Menurut penafsiran ini, maka dapat difahami bahwa ayat di atas menjelaskan tentang perintah kepada Rasulullah agar beliau menyampaikan apa-apa yang telah diwahyukan kepadanya. Maka dengan demikian, secara bahasa kata hadis dapat bermakna baru, dekat, berita, al-Quran, dan penyampaian berita.

Terjadi perbedaan dikalangan ulama hadis mengenai pengertian hadis itu sendiri secara istilah. Namun yang perlu difahami bahwa meskipun secara redaksional terdapat perbedaan diantara mereka, tapi dari segi maknanya sama sekali tidak kontradiktif. Muhammad 'Ajjaj al-Khatib memberikan definisi bahwa yang dimaksud dengan hadis ialah:

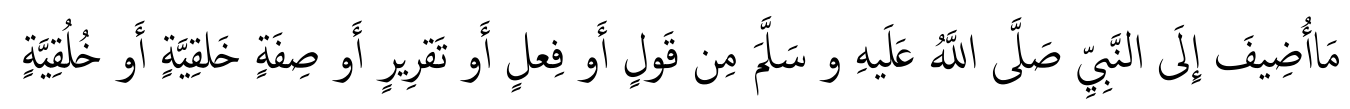

Artinya: Segala yang disandarkan kepada Nabi baik perkataan, perbuatan, ketetapan, atau sifat fisik dan psikis."(M. 'Ajjaj al-Khatib, 1973, hlm. 21)

Sifat fisik adalah hal-hal yang berkaitan dengan kondisi fisik atau jasmani Rasulullah seperti wajah, bentuk tubuh, tinggi badan, warna kulit, warna rambut, dan yang lainnya. Adapun yang berkenaan dengan sifat psikis adalah budi pekerti atau akhlak dan perilaku Nabi kepada Allah, diri sendiri, orang lain, serta lingkungan sekitar. 
Vol. 2 No. 2 (Desember 2019)

Muhammad Jamaluddin al-Qasimi memberikan definisi terhadap kata hadis sebagai berikut:

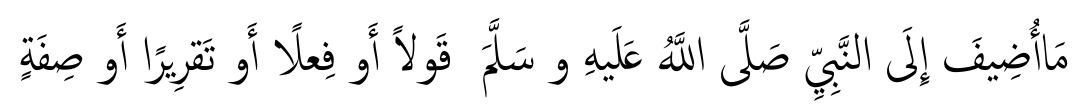

Artinya: Segala sesuatu yang disandarkan kepada Nabi baik berupa perkataan, perbuatan, ketetapan, maupun sifatnya."(al-Qasimi, t.t., hlm. 61)

Pendapat Ibn Taymiyyah tentang makna hadis yang juga dikutip oleh al-Qasimi, beliau mengatakan bahwa yang dimaksud dengan hadis itu secara mutlak adalah segala sesuatu yang berkenaan dengan apa-apa yang diberitakan dari Rasulullah setelah beliau diutus menjadi Nabi baik perkataan, perbuatan, maupun takrir (ketetapannya). Oleh sebab itu, walaupun Nabi hanya mengucapkan satu berita, maka wajib bagi umat Islam untuk mempercayai atau mengimaninya. Jika apa yang diucapkan oleh Nabi tersebut mengandung hukum wajib, haram, atau mubah, maka harus diikuti. Beberapa ayat al-Quran yang berkenaan dengan kenabian para nabi menunjukkan bahwa mereka adalah orang yang ma'sum atau terjaga dari berbuat kesalahan ketika menyampaikan ajaran-ajaran yang datang dari Allah. Maka sudah tentu apa yang mereka sampaikan benar adanya. Rasulullah diperintah untuk menyampaikan risalah Islam kepada seluruh umat manusia.(al-Qasimi, t.t., hlm. 62)

'Ajjaj al-Khatib mengatakan bahwa yang dimaksud hadis di kalangan ulama hadis adalah segala sesuatu yang berasal dari Nabi baik berupa perkataan, perbuatan, maupun ketetapannya baik sebelum atau setelah beliau diutus menjadi Rasul. Tetapi, pada umumnya kata hadis dimaksudkan kepada sesuatu yang berasal dari Nabi setelah beliau diangkat menjadi Rasul.

Berbeda dengan definisi yang diberikan oleh ulama hadis terhadapa kata hadis itu sendiri, maka para ulama usul fiqih mendefinisikan bahwa hadis itu adalah sunnah qauliyyah, sebab sunnah menurut mereka lebih bersifat umum dibanding hadis yang mencakup perkataan, perbuatan, dan ketetapan Nabi yang layak dijadikan dalil bagi hukum syara'. Maka dari itu, para ulama usul fiqih mendefinisikan Sunnah atau Hadis dengan:

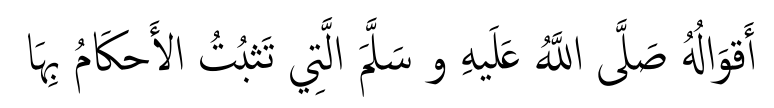

Artinya: Segala perkataan Nabi yang dapat dijadikan hujjah sebagai penetapan hukum syari'at."(M. 'Ajjaj al-Khatib, 1989, hlm. 72) 
Vol. 2 No. 2 (Desember 2019)

Melihat pengertian hadis dari sudut pandang para ulama usul fiqih, maka dapat difahami bahwa segala yang diucapkan Nabi yang tidak membawa misi kerasulan; seperti cara berpakaian, tidur, berbicara, makan minum dan apapun yang berkaitan dengan hal ihwal Nabi, bukanlah termasuk hadis.

Para ulama hadis memahami bahwa hadis adalah merupakan sinonim dari kata sunnah. Namun, pada umumnya hadis digunakan untuk pengertian segala sesuatu yang diriwayatkan dari Nabi setelah beliau diutus menjadi Rasul.(al-Farisi, 1992, hlm. 24) Sebagian ulama mengatakan bahwa hadis hanya terbatas pada apa-apa yang diucapkan dan dilakukan oleh Nabi. Adapun yang berkaitan dengan persetujuan dan sifat-sifatnya bukan termasuk hadis, sebab keduanya adalah perkataan dan perbuatan sahabat. Selain itu, hadis juga digunakan untuk sesuatu yang disandarkan kepada Allah yang dikenal dengan sebutan hadis qudsi, yaitu hadis yang disandarkan oleh Nabi kepada Allah. Disebut hadis karena berasal dari Rasulullah, dan dikatakan qudsi sebab disandarkan kepada kepada Allah. Dari sini pula terlihat dengan jelas perbedaan antara hadis dengan sunnah, sebab tidak pernah ada sebutan sunnah qudsiyah(Idri, 2017, hlm. 93).

\section{Pengertian Sunnah}

Sunnah secara bahasa berarti a way, course, rule, mode, or manner of acting or conduct of life (jalan, arah jalan, aturan, cara berbuat atau tingkah laku kehidupan). Kata sunnah serta bentuk jamaknya sunan disebutkan sebanyak lima belas kali beserta pengulangannya; yang berarti course of rule (arah suatu aturan), mode of life (cara hidup), line of conduct (garis-garis tingkah laku).('Azami, 1977, hlm. 3) Jika melihat pengertian sunnah dari segi etimologis, maka kata sunnah dapat pula berarti jalan hidup yang baik maupun yang buruk.(M. 'Ajjaj al-Khatib, 1989, hlm. 17) Sunnah juga dapat diartikan dengan jalan yang diridai atau tidak, bisa pula berarti kebiasaan.(alJurjani, t.t., hlm. 22) Pengertian sunnah secara bahasa ini sejalan dengan apa yang Nabi telah sabdakan dalam hadis yang diriwayatkan oleh Imam Muslim berikut:

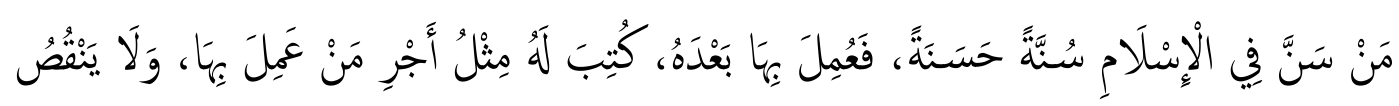

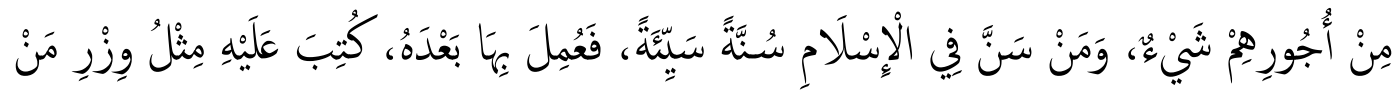

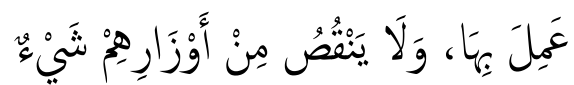

Artinya: Barangsiapa menjalani (memberi contoh) dalam Islam dengan jalan (contoh) yang baik, kemudian ada orang yang mengikutinya, maka ditetapkan 
Vol. 2 No. 2 (Desember 2019)

baginya pahala sebagaimana pahala orang yang mengamalkannya, dan tidak dikurangi sedikitpun dari pahala orang tersebut. Barangsiapa menjalani (memberi contoh) dalam Islam dengan jalan (contoh) yang buruk, kemudian ada orang yang mengikutinya, maka ditetapkan baginya dosa sebagaimana orang yang mengikutinya dan tidak dikurangi sedikitpun dari dosa orang tersebut. (HR. Muslim)(al-Naisaburi, 2003, hlm. 462)

Para ulama baik dikalangang hadis, usul fiqih, dan fiqih; memiliki pendapat yang berbeda-beda dalam mendefinisikan sunnah secara istilah sesuai dengan sudut pandang mereka terhadap Nabi Saw. Ulama hadis menilai bahwa Nabi adalah sebagai imam, pemberi petunjuk, pemberi nasihat, sebagai suri tauladan, dan panutan. Mereka menukil segala hal yang berkaitan dengan Nabi baik dari segi perkataan, perbuatan, ketetapan, ciri fisik dan budi pekerti baik berupa hukum syara' atau bukan.(M. 'Ajjaj alKhatib, 1989, hlm. 18) Melalui sudut pandang ini, maka ulama hadis mendefinisikan sunnah dengan:

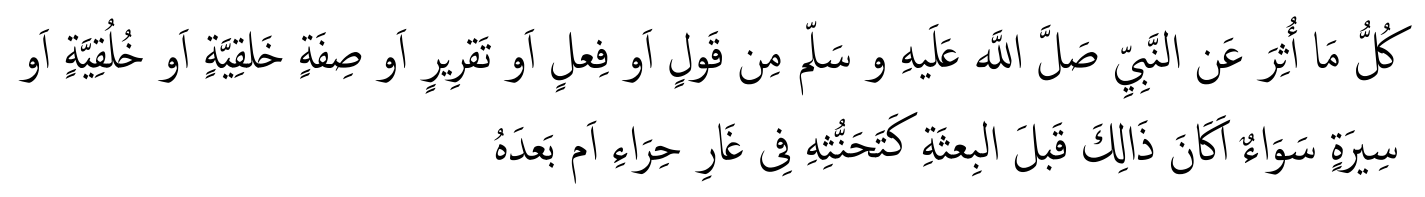

Artinya: Segala yang berasal dari Nabi berupa perkataan, perbuatan, persetujuan, sifat fisik dan budi pekerti, jalan hidup baik yang terjadi sebelum Nabi diutus menjadi rasul seperti ketika bertahan di Gua Hira ataupun sesudahnya.(M. 'Ajjaj al-Khatib, 1989, hlm. 19)

Dari paparan definisi sunnah secara istilah menurut ulama hadis, maka dapat difahami bahwasanya makna sunnah itu sangat luas menjangkau segala aspek kehidupan Nabi semenjak lahir hingga beliau wafat, sesudah diutus sebagai rasul atau sebelumnya, juga yang terkait dengan perkara yang menunjukkan hukum syara' atau tidak. Nabi dipandang secara totalitas dari sisi sebagai seorang pemimpin, pemberi petunjuk, pemberi nasihat, suri tauladan, baik setelah mendapatkan wahyu pertama dari Allah maupun sebelum itu ketika beliau belum diangkat menjadi nabi dan rasul. Mustafa A'zami mengatakan dalam bukunya Studies in Hadith Metodology and Literature sebuah pendapat yang dikutip dari pendapat al-Jazayri dalam Taujih al-Nazar bahwa menurut ulama hadis, yang dimaksud dengan sunnah itu adalah segala sesuatu yang berkenaan apa-apa yang ditransmisikan dari Nabi; perkataan, perbuatan, persetujuannya maupun deskripsi tentang sifat dan fisiknya.('Azami, 1977, hlm. 3) Selanjutnya, ketika mendefinisikan 
Vol. 2 No. 2 (Desember 2019)

sunnah, para ulama hadis menilai bahwa Nabi sebagai imam, pemberi petunjuk, contoh yang baik, dan panutan sehingga mereka meriwayatkan apapun yang berkenaan dengan beliau baik riwayat hidup, budi pekerti, berita, perkataan, perbuatan, baik yang mengandung hukum syara' atau tidak.(M. 'Ajjaj al-Khatib, 1973, hlm. 15)

Dalam penilaian ulama usul fiqih bahwa Nabi adalah sebagai penetap hukum serta peletak kaidah-kaidah bagi para mujtahid dalam menetapkan hukum Islam. Mereka memandang Nabi dari sisi perbuatannya yang bermuatan hukum syara'. Mereka membahas hukum syara' yang berupa wajib, haram, sunnah, mubah dan yang lainnya.(M. 'Ajjaj al-Khatib, 1989, hlm. 18) Karena ulama usul fiqih mengartikan sunnah adalah sesuatu yang bersumber dari Nabi yang ada kaitannya dengan hukum syara' baik berupa ucapan, perbuatan, maupun ketetapan, maka mereka memberikan pengertian terhadap sunnah dari segi istilah bahwa sunnah itu sebagai sumber hukum Islam:

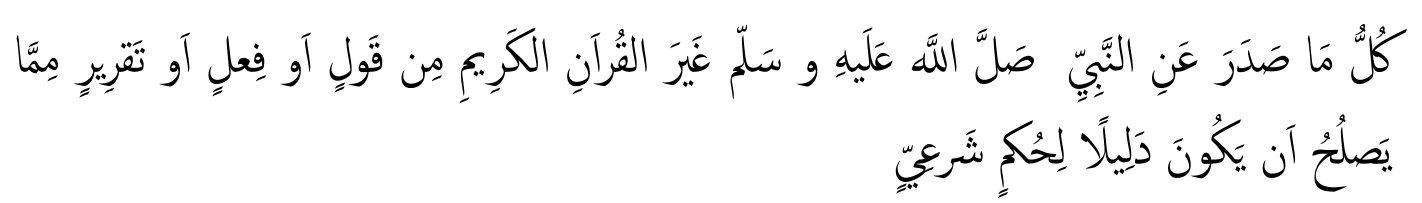

Artinya: Segala yang bersumber dari Nabi selain al-Quran baik perkataan, perbuatan, maupun persetujuan yang pantas menjadi dalil hukum syara'.(M. 'Ajjaj al-Khatib, 1989, hlm. 19)

Ulama usul fiqih mendefinisikan sunnah sebagaimana di atas berdasarkan pada penilaian mereka terhadap Nabi sebagai penetap hukum yang telah meletakkan kaidah-kaidah bagi para mujtahid sesudahnya dan menjelaskan undang-undang kehidupan bagi manusia, sehingga mereka hanya memfokuskan pada perkataan, perbuatan, dan ketetapan-ketetapan beliau yang dapat dijadikan sebagai dalil atas hukum dari suatu perkara.(M. 'Ajjaj al-Khatib, 1973, hlm. 15)

Dasar pemikiran dari para ulama usul fiqih sebagaimana yang telah disebutkan, sejalan dengan al-Quran ayat 7 dari surah al-Hasyr yang memerintahkan agar umat Islam menerima segala yang berasal dari Nabi dan meninggalkan apa yang dilarang oleh beliau. Dengan demikian, ulama usul fiqih secara khusus memandang nabi sebagai figur penetap hukum, subjek yang darinya keluar kaidah dan aturan-aturan hukum. Sementara itu, ulama fiqih mendefinisikan sunnah secara istilah dengan: 


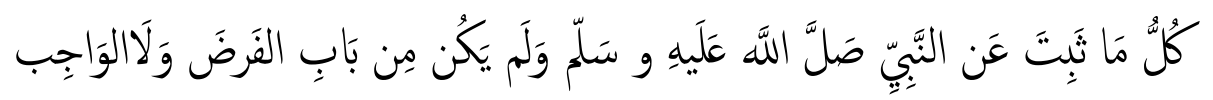

Artinya: Segala yang ditetapkan dari Nabi tetapi tidak termasuk yang fardu dan bukan pula yang wajib.(M. 'Ajjaj al-Khatib, 1989, hlm. 19)

Dalam memaknai sunnah ulama fiqih terfokus pada aspek praktisnya saja, yang mana mereka memandang bahwa Nabi adalah sosok yang perilakunya mengandung hukum syara'.(M. 'Ajjaj al-Khatib, 1989, hlm. 18) Mereka memfokuskan sunnah pada hukum syara' yang berkaitan dengan perbuatan mukallaf selain wajib dan fardu. Mereka melihat Nabi dari sisi perbuatannya yang menunjukkan hukum syar'i dan membahas hukum syara' dalam perbuatan mukallaf baik yang wajib, haram, mubah dan yang lainnya.(M. 'Ajjaj al-Khatib, 1973, hlm. 15) Oleh sebab itu, selain dipandang sebagai sebagai penyampai risalah, beliau juga dilihat sebagai sosok yang melaksanakan risalah tersebut sehingga apapun yang dilakukan dan diucapkan oleh Nabi ketika hal itu tidak berkaitan dengan hal yang wajib atau fardu, maka hal itu disebut sunnah. Pengertian sunnah menurut ulama fiqih ini kemudian diartikan sebagai suatu perbuatan yang jika dikerjakan oleh seseorang, maka pelakunya mendapat pahala, dan orang yang meninggalkannya tidak berdosa. Berbeda dengan wajib dan fardu yang pelakunya akan mendapat pahala dan orang yang meninggalkannya akan berdosa.(Idri, 2017, hlm. 96)

Selain kata sunnah, di kalangan ulama hadis juga dikenal kata khabar dan atsar untuk tujuan yang sama. Secara bahasa, arti dari kata khabar adalah sesuatu yang diucapkan atau dibicarakan.(Idri, 2017, hlm. 96) Sedangkan menurut istilah jumhur ahli hadis, khabar merupakan sinonim dari hadis, yaitu segala yang disandarkan kepada Nabi baik berupa perkataan, perbuatan, maupun ketetapan. Khabar dan hadis juga meliputi segala yang berasal dari sahabat atau tabi'in. Menurut pendapat ini, khabar atau hadis mencakup hadis marfu', mauquf, dan maqtu'(M. 'Ajjaj al-Khatib, 1989, hlm. 27). Sebagian mereka berpendapat bahwa hadits khusus untuk sesuatu yang berasal dari Nabi, sedangkan khabar untuk sesuatu yang berasal dari selain Nabi. ada pula yang berpendapat bahwa hadis mencakup khabar, dan tidak dengan sebaliknya. Jadi menurut pendapat yang terakhir ini, hadis memiliki makna yang lebih luas daripada khabar. Khabar yang marfu' dan mauquf menurut ulama hadis disebut atsar. Menurut ahli fiqih Khurasan, hadis yang marfu' disebut dengan khabar, dan hadis yang mawquf disebut atsar. (M. 'Ajjaj al-Khatib, 1989, hlm. 28).

Hadis dan atsar merupakan dua kata yang mempunyai arti yang sama, yaitu sesuatu yang disandarkan kepada Nabi baik berupa perkataan, 
Vol. 2 No. 2 (Desember 2019)

perbuatan, maupun ketetapan. Secara bahasa atsar berarti yang tersisa dari sesuatu. Sebagian ulama mendefinisikan atsar dengan sesuatu yang berasal dari sahabat dan tabi'in. Dengan demikian, menurut sebagian ulama, atsar khusus untuk hadis yang berasal dari sahabat (mauquf) dan tabi'in (maqtu'). Sedangkan ulama yang lain menyebutkan bahwa atsar untuk hadis yang berasal dari Nabi (marfu'), sahabat (mauquf) dan tabi'in (maqtu').(Nirwana, 2012, hlm. 293)

Sunnah adalah antonim dari kata bid'ah (perkara baru) dalam agama yang oleh Nabi sendiri hal itu tidak pernah dilaksanakan. Maka dari itu, segala amalan yang ada atau dicontohkan oleh Nabi adalah termasuk dalam kategori sunnah. Atau dalam makna yang lain, kata sunnah bukan hanya dimaksudkan untuk perkara atau sesuatu yang disandarkan kepada Nabi semata. Namun, sunnah juga dapat bermakna segala sesuatu yang disandarkan kepada para sahabat dan tabi'in. Pengertian sunnah yang ini tergambar dalam hadis Nabi berikut:

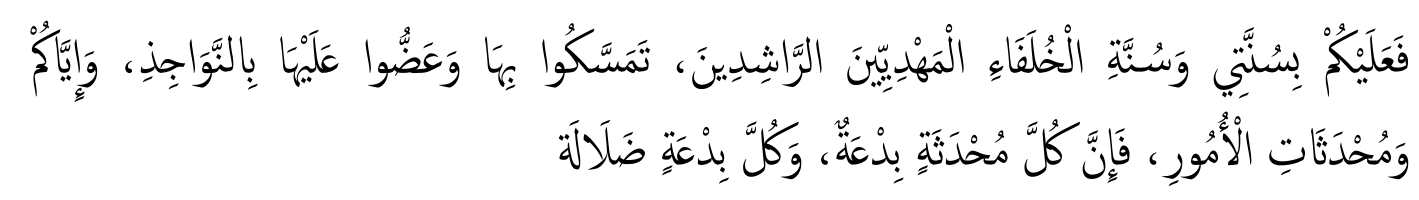

Artinya: Wajib bagi kalian berpegang teguh kepada sunnahku dan sunnah khulafa'u al-rasyidin. Gigitlah ia dengan gigi geraham kalian. Dan berhatihatilah terhadap perkara baru yang diada-adakan dalam agama, karena setiap perkara yang baru dalam agama itu adalah bid'ah, dan setiap bid'ah itu sesat." (H.R. Abu Daud)(Abu Daud, t.t., hlm. 832)

\section{Ragam Pemakaian Istilah Sunnah Di Indonesia}

Umat Islam Indonesia dikenal dengan sensitifitas keislamannya. Mereka sangat sensitif dengan bentuk-bentuk pengemasan Islam yang sifatnya khas. Sehingga dengan mudahnya trend ini mendapat tempat di hati sebagian umat Islam di sini. Apalagi mendapat kesempatan untuk diekspos media massa, baik berupa media cetak maupun elektronik yang semakin meluaskan pengaruhnya. Tentunya trend islami ini akan mudah diterima oleh kalangan masyarakat yang mayoritas muslim. Ini tentunya peluang yang sangat menguntungkan bagi orang yang berpikiran bisnis. Maka trend Islami inipun berubah menjadi budaya massa. Seiring dengan itu, arus kapitalisme pun mulai mempengaruhi trend-trend budaya massa tadi. Mereka berasumsi bisa memetik keuntungan yang besar dari fenomena ini. Sehingga trendtrend islami ini menjadi komoditas yang menggiurkan bagi mereka. Akhirnya 
Vol. 2 No. 2 (Desember 2019)

simbol-simbol agamapun dijual atau dibisniskan dan menjadi stok kebutuhan pasar, termasuk kata sunnah.

Setelah dilakukan penelitian melalui aplikasi facebook, instagram, youtube dan aplikasi internet lainnya, terdapat beberapa kata sunnah yang disandarkan pada objek tertentu; mulai dari penggunaan kata sunnah untuk beberapa toko online shop, komunitas, radio, tv, sampai kepada nama dari beberapa yayasan yang juga dilekatkan kata sunnah dalam penamaannya. Berikut ragam dari penamaan yang dimaksud:

\section{Toko Online Shop}

1) Zain Sunnah Clothing, nama dari sebuah toko yang berlokasi di Jl. Rawa Bola No.45A, Cibubur, Ciracas, Jakarta Timur.

2) Bunayya Sunnah Clothing, nama dari sebuah toko yang berlokasi di Perumahan Sawangan Permai, Jl. Permata VIII, Blok C II/27, Sawangan, Jawa Barat.

3) Sunnah Store Rengat, nama dari sebuah toko yang berlokasi di Plaza Rengat, Jl. Bupati Tulus Lantai Dasar, Rengat, Riau.

4) Counter as-Sunnah, nama dari sebuah toko yang berlokasi di Jl. Sebelas April, depan Masjid Besar Tegal Kalong, Sumedang.

5) As-Sunnah Fashion, nama dari sebuah toko yang berlokasi di Jl. Pangeran Santri No. 205, Gg. Sitet, Sumedang Selatan, Sumedang.

6) Warung Sunnah, nama dari sebuah toko yang berlokasi di Jl. Cendrawasih II, B7 No. 01, PSI, Kota Tangerang.

7) Sunnah Beard Club, nama dari sebuah toko yang berlokasi di Gg. Jarum Kukupu No. 19, RT.07/RW.08, Cibadak, Kec. Tanah Sereal, Kota Bogor, Jawa Barat.

\section{Komunitas}

1) Bikers Sunnah Indonesia, nama dari klub motor dengan tagline One God, One Prophet, One Ummah yang digagas dan dibentuk pada bulan Juni 2017 oleh seseorang yang bernama Deedat. (Yani, 2017)

2) Sunnah Diaries, nama dari salah satu Facebook Fans Page, dengan jumlah 9.892 anggota. Group Sunnah Diaries adalah group untuk belajar, berbagi ilmu, mengumpulkan faedah-faedah ilmiah seputar: alQuran dan Sunnah, hukum Syari'at, fatwa Ulama Salaf, aqidah dan manhaj Salafiyah, fiqih ibadah dan muamalah, seputar hukum dan fatwa, serta adab dan akhlak. Group ini berkomitmen untuk senantiasa di atas Manhaj Salaf. Jauh dari kelompok sesat, jauh dari perbuatan bid'ah dan syirik, jauh dari kelompok Khawarij, jauh dari kelompok 
dan ajaran baru yang menyimpang.("PERATURAN GRUP SUNNAH DIARIES," 2017)

3) Sahabat Sunnah, nama dari sebuah Group Facebook yang dibuat pada tanggal 16 November 2015, dengan jumlah 7.899 anggota.

\section{Pesantren}

1) Pesantren Minhajus Sunnah, Jl.Raya Darmaga Belakang Gudang Bulog, Darmaga, Bogor, Jawa Barat.

2) Pesantren Ihya As-Sunnah, Jl. Terusan Paseh - BCA No. 11 Tasikmalaya.

3) As-Sunnah Cirebon, Jl. Kali Tanjung 52.B Situ Gangga Karya Mulya Kesambi, Kota Cirebon.

4) Cahaya Sunnah, Jl. Pahlawan, Kampung Tengah RT. 03/ RW. 03 Cileungsi, Bogor.

5) Pesantren as-Sunnah, Jl. Baji Rupa, Kota Makassar, Sulawesi Selatan.

\section{Masjid}

1) Masjid As-Sunnah Rempung, Jl. Jurusan Rempung-Pancor, Desa Rempung, Lombok Timur.

2) Masjid as-Sunnah, Desa Sumoli, Kabupaten Tojo Una-una, Sulawesi Tengah.

3) Masjid as-Sunnah Jorong, Desa Sembalun Bumbung, Lombok TimurNTB.

4) Masjid as-Sunnah, Kampung Brugak Mujur, Desa Sembalun Timba Gading, Kec. Sembalun-Lombok Timur.

5) Masjid as-Sunnah Pringgasela, Lombok Timur-NTB.

6) Masjid as-Sunnah, Komplek Griya Bandung Asri2, Blok H3 No. 1, RW. 02, Cipagalo, Kec. Bojongsoang-Bandung.

\section{Stasiun TV}

1) Sunnah TV Indonesia ("SUNNAH TV INDONESIA," t.t.)

2) TVSunnah (TVSunnah Podcast, t.t.)

\section{Radio}

1) Radio Sunnah (Radio Sunnah, t.t.)

2) Radio Tarbiyah Sunnah 1476 AM, nama stasiun radio yang berlokasi di Desa Selacau, Kampung Lembur Tengah, Batujajar, Kabupaten Bandung Barat.

3) Suara Sunnah 88,5 FM (Suarasunnah, t.t.) 


\section{Yayasan}

1) Yayasan Tarbiyah Sunnah Bandung (YTS), Jl. Jalan Jurang No. 86, Pasteur, Sukajadi, Kota Bandung.

2) Yayasan Padasuka Sunnah, Jl. Kolonel Masturi No. 85-Cimahi.

3) Yayasan Permata Sunnah, Kp. Pengodokan, RT.04/RW.02 Kelurahan Kutabaru, Kec. Pasar Kemis-Tangerang.

4) Yayasan Babussalam As-Sunnah, Radar Auri Jl. Swadaya 3 No. 40, RT. 005/RW. 011, Kelurahan Mekarsari, Cimanggis-Jawa Barat.

Beragam istilah yang telah disebutkan di atas, hanyalah sebagian kecil dari sekian banyak objek yang diselipkan kata sunnah dalam penamaannya. Bahkan, dalam salah satu kesempatan pada acara tablig akbar yang dilaksanakan pada tanggal 28 September 2018 di Lapangan Umum Desa Sembalun, Kec. Sembalun, Kabupaten Lombok Timur, dan disiarkan langsung oleh Rodja TV; Yazid bin Abdul Qadir Jawwaz pada menit ke 30 detik ke 16 mengatakan "Dengan adanya gempa ini, banyak 'Ustad-ustad Sunnah' yang datang untuk bertemu antum." (NASIHAT DALAM MENGHADAPI MUSIBAH ( LOMBOK) Ustadz Yazid Jawas, 2018)

Pernyataan Yazid bin Abdul Qadir Jawwaz di atas tentu menimbulkan tanda tanya di kalangan masyarakat, jika ada ustad sunnah, apakah dengan begitu menandakan adanya ustad bid'ah? Labelisasi semacam itu lahir dari sikap tergesa-gesa mengambil kesimpulan. Seakan-akan ketika ada ulama yang menyelisihi sunnah menurutnya, otomatis dianggap ulama bid'ah.

Begitu pula dengan berbagai macam penamaan pada objek-objek yang telah disebutkan sebelumnya. Jika difahami secara sepintas, maka masyarakat akan berasumsi bahwa baik itu komunitas, radio, tv, dan objekobjek lainnya yang tidak menggunakan kata sunnah dalam penamaannya; apakah objek-objek tersebut adalah bid'ah?

Jika terjadi hal seperti ini, maka yang akan muncul adalah perpecahan dan sikap saling menyalahkan. Padahal belum tentu sesuatu yang dilabeli dengan kata sunnah betul-betul menjalankan sunnah atau sesuai dengan sunnah yang dimaksud, terlebih ketika hal tersebut berkaitan dengan hal komersil seperti toko dan sebagainya. Dari sekian banyak nama yang menggunakan kata sunnah, dapat dilihat banyaknya kejanggalan. Mulai dari pergeseran penggunaan kata sunnah, sampai kepada asumsi bahwa kata sunnah tersebut digunakan oleh sejumlah oknum hanya untuk kepentingan komersial belaka. Misalnya untuk menarik minat pengunjung atau pembeli.

Bahkan Abdul Hakim bin Amir Abdat dalam salah satu ceramahnya ketika ditanya tentang orang yang menggunakan kata sunnah untuk suatu 
Vol. 2 No. 2 (Desember 2019)

objek tertentu seperti Bikers Sunnah, maka beliau memberikan tanggapan bahwa apa yang dilakukan oleh orang tersebut adalah perbuatan yang salah dan menyimpang. Bahkan beliau menambahkan bahwa perbuatan yang seperti itu adalah perbuatan jahil dan tidak boleh dilakukan oleh siapapun. (Bikers Sunnah, Laundry Sunnah, Perumahan Sunnah, dsb-Ustadz Abdul Hakim bin Amir Abdat, 2019)

\section{PENUTUP}

Sunnah adalah segala sesuatu yang bersumber atau disandarkan kepada Nabi Saw. selain dari yang wajib. Sunnah adalah antonim dari kata bid'ah (perkara baru) dalam agama yang oleh Nabi sendiri hal itu tidak pernah dilaksanakan. Maka dari itu, segala amalan yang ada atau dicontohkan oleh Nabi adalah termasuk dalam kategori sunnah. Atau dalam makna yang lain, kata sunnah bukan hanya dimaksudkan untuk perkara atau sesuatu yang disandarkan kepada Nabi semata. Namun, sunnah juga dapat bermakna segala sesuatu yang disandarkan kepada para sahabat dan tabi'in. Di Indonesia, kata Sunnah telah mengalami pergeseran makna, kata sunnah tidak lagi hanya dimaksudkan sebagai hal yang bersumber dari Nabi namun telah meluas menjadi label-label diberbagai produk, toko, komunitas bahkan yayasan. Merupakan suatu kesalahan apabila kata sunnah digunakan untuk penamaan suatu objek, sebagaimana yang terjadi di Indonesia yang jelasjelas tidak pernah terjadi di zaman Rasulullah; baik yang secara langsung dilakukan oleh beliau, Sahabat maupun Tabi'in. Hal ini akan memunculkan asumsi bahwa baik itu para Ustadz, toko, komunitas, radio, tv, dan objekobjek lainnya yang tidak menggunakan kata sunnah dalam penamaannya akan dianggap bid'ah dan konsekuensinya adalah ummat akan menjauh serta akan muncul sikap meremehkan dan saling menyalahkan yang akan menimbulkan perpecahan. Jika-pun memang harus memakai kata sunnah untuk nama suatu objek, maka hal itu harus diakui hanya sebatas label saja dan bukan untuk menunjuk pada makna dari kata sunnah yang sebenarnya.

\section{REFERENSI}

Abu Daud, S. bin al-Asy'ats al-Sijistani. (t.t.). Sunan Abi Daud. Riyadh: Maktabah al-Ma'arif.

al-Bukhari, M. bin I. A. A. (1422). Al- Jami'u al- Musnadu al- Shahihu alMukhtasharu min Umuri Rasulillah Sallallahu 'Alaihi wa Sallam wa Sunanihi wa Ayyamihi (Vol. 5). Daru Thauqi al- Najati.

al-Farisi, M. ibn M. ibn 'Ali. (1992). Jawahiru al-Ushuli fi 'Ilmi Hadits al-Rasul. Beirut: Dar al-Kutub al-Ilmiyah. 
al-Jurjani, A. bin M. al-Sayyid al-Syarif. (t.t.). Al-Ta'rifat. Jeddah: al-Haramain. al-Khatib, M. 'Ajjaj. (1973). Al-Sunnah qabla al-Tadwin. Beirut: Dar al-Fikr.

al-Khatib, M. 'Ajjaj. (1989). Usulu al-Hadits 'Ulumuha wa Musthalahuh. Beirut: Dar al-Fikr.

al-Naisaburi, M. bin al-H. A. al-H. al-Q. (t.t). Al- Musnadu al- Shahihu alMukhtasharu bi Naqli al- 'Adli 'Ani al- 'Adli Ila Rassulillahi Sallallahu 'Alaihi wa Sallam (Vol. 3). Beirut: Dar Ihya'i al- Turatsi al- 'Arabi.

al-Naisaburi, M. bin al-H. A. al-H. al-Q. (2003). Al- Musnadu al-Shahihu alMukhtasharu bi Naqli al- 'Adli 'Ani al- 'Adli Ila Rassulillahi Sallallahu 'Alaihi wa Sallam. Beirut: Dar al-Fikr.

al-Qasimi, M. J. al-Din. (t.t.). Qawa'id al-Tahdits min Funun Musthalah alHadits. Beirut: Dar al-Kutub al-Ilmiyah.

al-Sabbagh, M. (1972). Al-Haditsu al-Nabawi. Riyadh: al-Maktab al-Islami.

al-Salih, S. (1988). Ulumu al-Hadits wa Mustalahuh. Beirut: Dar al-'Ilm li alMalayin.

Al Siba'i, M. (1994). Al Sunnah wa Makanatuha fi al Tashri' al Islami. Kairo: Dar al Qawmiyyat li al Thaba'ah wa al Nashr.

'Azami, M. M. (1977). Studies in Hadith Metodology and Literature. Indianapolis: American Trust Publication.

Bikers Sunnah, Laundry Sunnah, Perumahan Sunnah, dsb-Ustadz Abdul Hakim bin Amir Abdat [MP4]. (2019). Diambil dari https://www.youtube.com/watch?v=zZ4CiHrGSi4\&feature=youtu.be Idri. (2017). Hadis dan Orientalis. Depok: PT Balebat Dedikasi Prima.

Kodir, A. A. (2016). Sejarah Bid'ah: Ashhab al-Hadith dan Dominasi Wacana Islam Autentik pada Tiga Abad Pertama Hijriyah. Wawasan: Jurnal Ilmiah Agama dan Sosial Budaya, 1.

NASIHAT DALAM MENGHADAPI MUSIBAH ( LOMBOK) Ustadz Yazid Jawas [MP4]. (2018). Diambil dari https://www.youtube.com/watch?v=yaj5dnYuzGM\&feature=youtu.be Nirwana, D. (2012). REKONSEPSI HADITS DALAM WACANA STUDI ISLAM: Telaah Terminologis Hadits, Sunnah, Khabar, dan Atsar. Jurnal EduIslamika.

PERATURAN GRUP SUNNAH DIARIES [Facebook]. (2017, September 22). Diambil 19 Oktober 2019, dari Sunnah Diaries website: https://free.facebook.com/groups/1634027486664539?view=perma link\&id=1676353462431941\&_rdc=1\&_rdr

Radio Sunnah. (t.t.). Diambil dari https://tunein.com/radio/Radio-Sunnahs263339/

Suarasunnah. (t.t.). Diambil dari http://suarasunnahpaser.com/ 


\section{AT-TIBYAN}

Journal Of Qur'an and Hadis Studies

Vol. 2 No. 2 (Desember 2019)

SUNNAH TV INDONESIA [Dynamic Website]. (t.t.). Diambil dari SUNNAH TV INDONESIA website: https://sunnahtvindonesia.blogspot.com/

TVSunnah Podcast. (t.t.). Diambil dari https://www.tvsunnahpodcast.com/

Yani, M. (2017, Juli). Bikers Sunnah, Menabur Benih Kebaikan Sebagai Komunitas Motor [Berita]. Diambil 19 Oktober 2019, dari Merahputih.com website: https://merahputih.com/post/read/bikerssunnah-menabur-benih-kebaikan-sebagai-komunitas-motor 